\title{
THE CHANGES OF SPECTRAL LINE CONTOURS OF P CYGNI
}

\author{
F(Presented by J. Einasto)
}

$\mathrm{P}$ Cygni is one of the most thoroughly investigated nonstable supergiant stars. Because of its brightness, P Cygni is observable with high spectral resolution and in a large range of wavelengths. The main properties of P Cygni can be explained in the framework of three-zonal models of its envelope [ $\left.{ }^{1-3}\right]$. Unfortunately, majority of detailed spectroscopic investigations show an inexhaustible variety of small variations of spectral lines $\left[{ }^{4-8}\right]$. Some of these papers are based on the comparison of the contours obtained during a few nights, others - on the comparison of mean annual contours determined once a year in the course of one month. From the data of these observations, it is possible to conclude that the variations of spectral line contours are really present, but we cannot tell how they vary. The present paper represents an attempt to find a preliminary answer to this problem using the data of the observations made during seven successive months.

Using the 2-meter reflector with coude spectrograph homogeneous spectroscopic material was obtained at the National Astronomical Observatory of the Bulgarian Academy of Sciences in the summer of 1981. This report includes a preliminary analysis of the spectral line profile details and their variations found using the $9 \AA / \mathrm{mm}$ spectrograms photographed on the IIaO Kodak plates with approximate intervals of 2 weeks and covering the spectral range of $3500-4700 \AA$.

For a preliminary investigation, four representative spectral lines of hydrogen $\left(\mathrm{H}_{\delta}, \mathrm{H}_{9}, \mathrm{H}_{10}\right.$ and $\left.\mathrm{H}_{14}\right)$ and one line of neutral helium $(\lambda 4026)$ were registered by the microphotometer. The spectral line contours (after transforming into intensities by the ordinary procedure) are given in Fig. 1, $a, b$, where the changes of these contours are markable.

The analysis of the observed changes of spectral line contours is based on the three-zonal models according to $\left[{ }^{1-3}\right]$. In accordance with these models the dissipation of the mechanical energy of pulsations in the core of a very massive star accelerates the outer layers of this star by the mechanism described in $\left[{ }^{9,10}\right]$. The accelerated material flows out of the star and is decelerated by the force of gravity. The outflow continues with deceleration until the acceleration caused by the radiative pressure in spectral lines (the CAK mechanism [ $\left.{ }^{11}\right]$ ) is switched in if the density of the envelope has become small enough. In Fig. 2 the structure of the three-zonal model is presented with the following descriptive functions being used: $v(R), n_{e}(R)$ and $v_{e s c}(R)$. The function $v(R)$ describes outflow velocity, $n_{e}(R)$ - electron density and $v_{e s c}(R)-$ escape velocity as a function of stellar radius.

According to the three-zonal model, the absorption components are formed in the inner part of the envelope, and the velocity field together with the density distribution yields to the formation of two absorption components. The shapes of the spectral line contours highly depend on these structures. We may count at least two factors which can strongly 

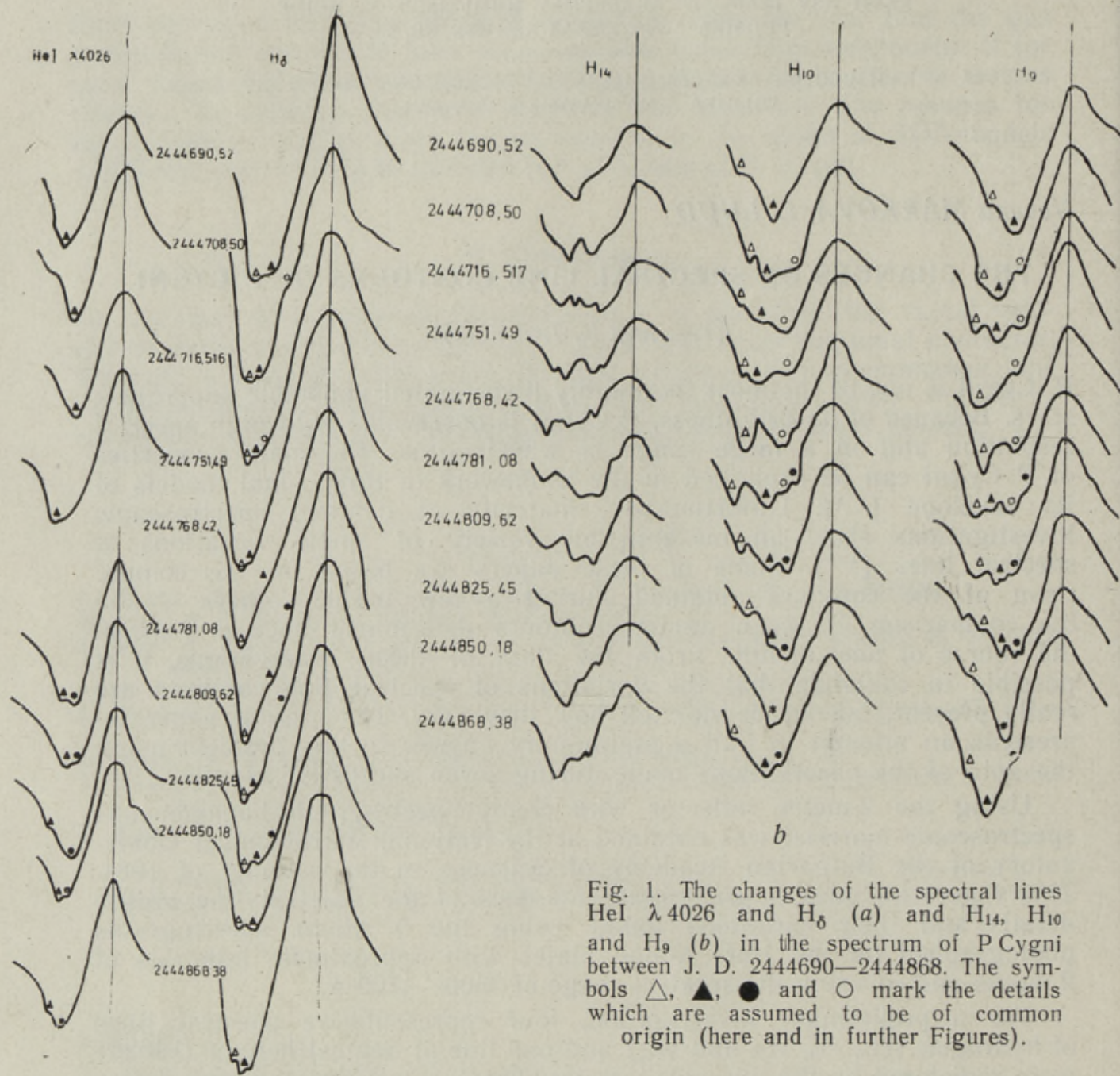

Fig. 1. The changes of the spectral lines HeI $\lambda 4026$ and $\mathrm{H}_{\delta}(a)$ and $\mathrm{H}_{14}, \mathrm{H}_{10}$ and $\mathrm{H}_{9}(b)$ in the spectrum of P Cygni between J. D. $2444690-2444868$. The symbols $\triangle, \boldsymbol{\Delta}, \boldsymbol{O}$ and $O$ mark the details which are assumed to be of common origin (here and in further Figures).

$a$

determine profile variations. First, if the fluctuations of outflow velocity are present. It is even possible that in some time-intervals of the deceleration zone we do not have any markable decrease in outflow velocity and the function $v(r)$ may even be monotonously nondecreasing. In such cases one can hardly see the two-component absorption. For example, in the cases of $\zeta$ Ori and $\zeta^{1}$ Sco $\left[{ }^{12,13}\right]$. Secondly, the density fluctuations due to the varying amount of material (fluctuating $n_{e}$ ). In this case the presence of more line components is possible. If we use the structure of the three-zonal model given in Fig. 2 and $R_{0}=64 R_{\odot}\left[{ }^{14}\right]$ for rough evaluations of the characteristic times of such variations, it turns out that the material passes the zone of inner acceleration in the course of $3-7$ days and both inner zones during 15 to 25 days. Therefore, we suppose that there exist variations with characteristic times from a few days to tens of days. The characteristic times of variations may be even longer.

Luud et al. $\left[{ }^{15}\right]$ reported changing radial velocities with a period of 57 days. We suppose that the changes of profiles have very different characteristic times. If we could observe the existing times of certain spectral details, it would also be possible to analyse their origin. There- 


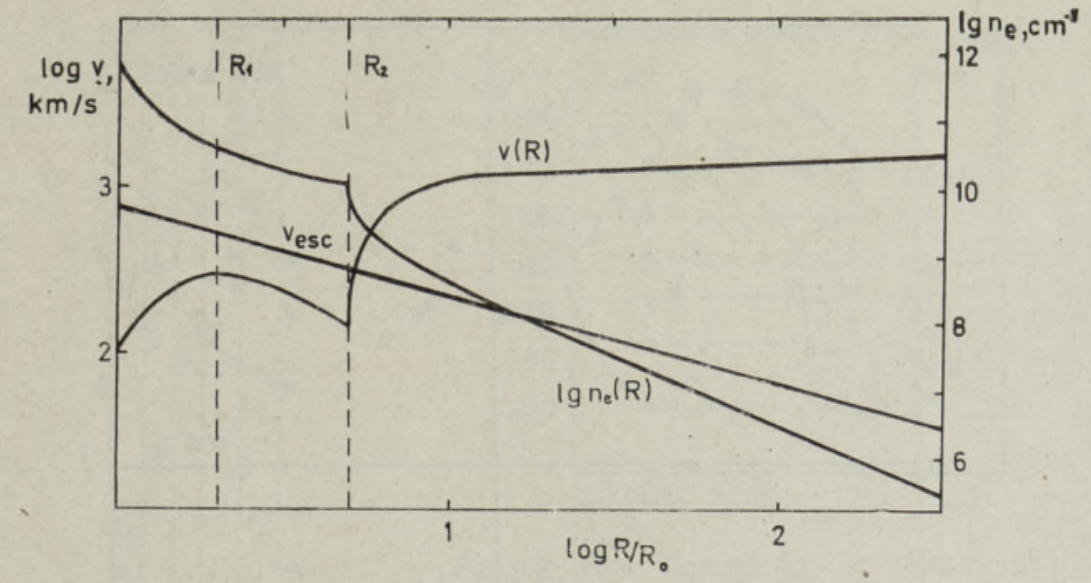

Fig. 2. The scheme of the three-zonal structure of the PCygni envelope.

fore, we must analyse our contours to find the details existing during a few days or more in their movement which changes the shape of spectral line profiles by displacing the line details according to their outflow velocity in changing the velocity field. Having described above our starting point, we shall further analyse the changes of spectral line contours.

From Fig. 1, $a, b$ we can see that the shapes of the profiles are strongly changing within a characteristic time of tens of days. The changes in the hydrogen lines $\mathrm{H}_{9}$ and $\mathrm{H}_{10}$ are usually very similar, which suggest that there may be real changes of velocity field or density distribution in the places of stellar atmosphere where these lines are formed. The $\mathrm{H}_{14}$ line is placed on the less dense part of the spectrograms, and the relatively low signal-to-noise relation made their analysis very difficult. Systematic changes are also detectable in hydrogen $\mathrm{H}_{\delta}$ profile. At the same time the $\lambda 4026$ profile also shows variations of radial velocity and the appearance of two components. The displacements of the marked details of the contours are shown in Fig. 3 where the same symbols as in Fig. 1, $a, b$ have been used.

All hydrogen lines have a component displaced approximately $-200 \mathrm{~km} / \mathrm{s}$ with variations of $\pm 20 \mathrm{~km} / \mathrm{s}$. This component is not present in the HeI $\lambda 4026$ line contours.

The second component of hydrogen lines with strongly varying displacements between -120 and $-180 \mathrm{~km} / \mathrm{s}$ is also present all the time, only around the J.D. 2444751 it seems to join the first component. This component is also present in the contours of HeI $\lambda 4026$ line as a strongly varying mean feature.

The third component appeares only in hydrogen lines between J.D. 2444708 and 2444781. In $\mathrm{H}_{\delta}$ line it seems to join the second component, but in $\mathrm{H}_{9}$ and $\mathrm{H}_{10}$ the contours seem to vanish.

The fourth components appear as the nearest to the emission component at J.D. 2444781. They rapidly displace to the violet, and they are also present in the $\mathrm{HeI} \lambda 4026$ lines. In the case of $\mathrm{H}_{9}$ and $\mathrm{H}_{10}$ lines, these components seem to join the second component of lines.

In the framework of the three-zonal model of P Cygni envelope it is very likely that the first components are due by the fall of the density decrease in the deceleration zone far enough from the star's boundier that the HeI $\lambda 4026$ line can form. The fluctuations of outflow velocity in other components and the frequently recurring trends of velocity to the largest outflow velocities are probably connected with nonuniform 


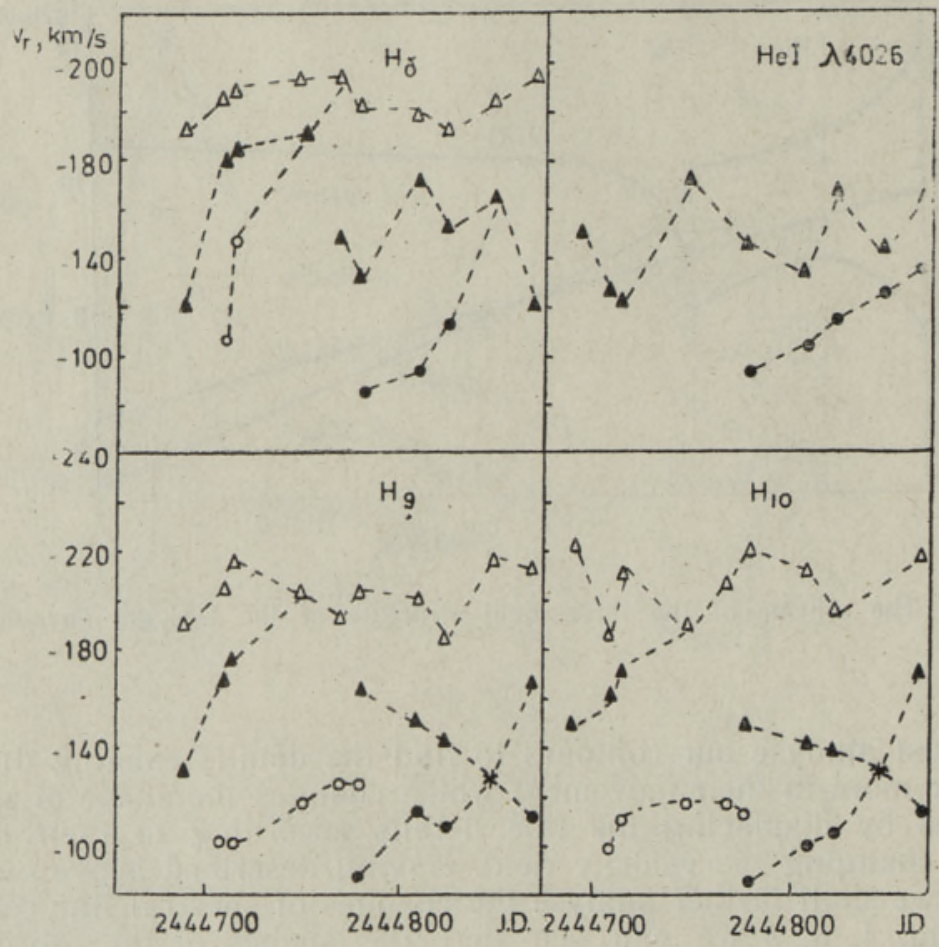

Fig. 3. The displacement changes of the spectral line details marked in Fig. 1, $a, b$.

outflow in the inner acceleration zone. The characteristic times of such variations are in the order of tens of days. This is the period of time model evaluations have supposed to be necessary for material outflow through the two inner zones.

Therefore, in the inner outflow zones the lumpy structure of the PCygni envelope is formed (observed with VLA for outer parts of envelope $\left.\left[{ }^{16}\right]\right)$.

There is one more important phenomenon in the shapes of spectral line contours - it is the timely appearance of many small components in the lines of easy elements. For example, the lines of NII(5) multiplet during J.D. $2444690-2444718$ had six components without detectable changes of their displacements. These displacements for one line $\lambda .4601$ are shown in Fig. 4. We cannot find each of the six components in all the lines, they are distorted by the plate noise. Clearly detected peaks are always present only at definite wavelengths. To persuade in the reality of these displacements, we give the mean values of the displacements and their dispersion as determined for all the lines from 8 spectrograms (Table).

\begin{tabular}{c|c|c|c|c|c|c}
\hline$\lambda$ & $v_{1}$ & $v_{2}$ & $v_{3}$ & $v_{4}$ & $v_{5}$ & $v_{6}$ \\
\hline 4601 & $158.8 \pm 5.9$ & $138.3 \pm 2.9$ & $124.6 \pm 2.6$ & $107.9 \pm 4.3$ & $90.0 \pm 6.5$ & $61.4 \pm 4.5$ \\
4607 & $165.0 \pm 4.6$ & $144.7 \pm 3.9$ & $126.6 \pm 4.5$ & $109.5 \pm 4.2$ & $90.7 \pm 8.5$ & $62.9 \pm 5.3$ \\
4613 & $161.2 \pm 5.3$ & $143.2 \pm 4.3$ & $122.5 \pm 4.3$ & $104.5 \pm 3.9$ & $90.5 \pm 4.2$ & $60.6 \pm 4.3$ \\
4621 & $158.2 \pm 3.6$ & $140.4 \pm 4.7$ & $122.1 \pm 3.7$ & $104.7 \pm 5.6$ & $86.0 \pm 6.8$ & $61.2 \pm 1.8$ \\
4630 & $157.2 \pm 2.9$ & $136.9 \pm 5.1$ & $119.7 \pm 2.9$ & $107.0 \pm 3.7$ & $90.2 \pm 6.4$ & $64.7 \pm 6.8$ \\
\hline mean & $160.08 \pm 3.12$ & $140.70 \pm 3.26$ & $123.10 \pm 2.62$ & $106.72 \pm 2.14$ & $89.44 \pm 1.95$ & $62.16 \pm 1.66$ \\
\hline
\end{tabular}




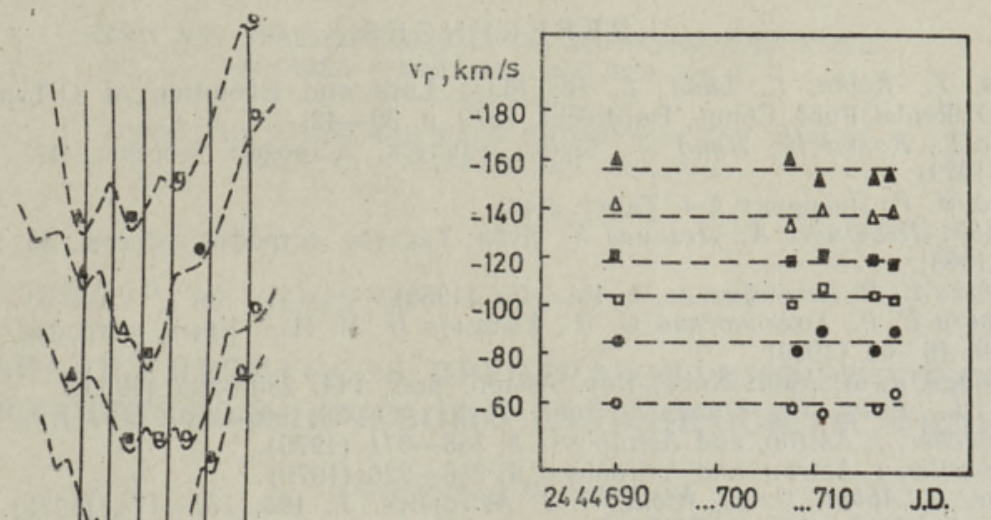

Fig. 5. Time dependence of the mean displacements of N II(5) line components. The dispersions of the velocities are smaller than the diameter of the symbols.

Fig. 4. The absorption components of N II(5) $\lambda 4601$ spectral line show the appearance of the peaks at the time of definite displacements. Each peak is not seen in all the contours.

From Table it follows that the components are well-defined and very clearly separate from one another. Hence, the evidence of the existence of such components is quite strong. Fig. 5 is an illustration of the dependence of these six components on time. Fig. 5 also demonstrates the nonvariability of these components.

The main conclusions of this preliminary analysis of the P Cygni spectral line variations are listed below.

1. The absorption components of the hydrogen lines are very complicated. Sometimes the hydrogen lines comprise even four components.

2. The characteristic times of variations are present in the scale of tens of days.

3. The absorption lines of NII (5) multiplet show multicomponent structure with well-defined time displacements non-varying in time.

4. The variability can qualitatively be explained by the lumpiness of the outflying material.

It is difficult to ascertain the physical significance of these results as our observations were made during too short an observation period. In order to find clearly established explanations for these variations in terms of any PCygni model, we need more extensive homogeneous observations.

We wish to thank K. Ummik and T. Saar for their technical assistance during the preparation of the manuscript. L. Luud is also very grateful to the Bulgarian Academy of Sciences for their generous hospitality at the National Astronomical Observatory. 
1. Nugis, T., Kolka, I., Luud, L. In: Mass Loss and Evolution of O-Type Stars. D. Reidel Publ. Comp., Dordrecht, 1979, p. 39-42.

2. Нугис Т., Колка И., Лууд Л. Публ. Тартуск. астрофиз. обсерв., 47, 191-211 (1979)

3. Колка Н. Р. Препринт А-4. Тарту, 1980.

4. Лууд Л., Пылдметс А., Леэсмяе Х. Публ. Тартуск. астрофиз. обсерв., 36, 211-221 (1968)

5. Астафьев E. P. Астрофизика, 4, 461-467 (1968).

6. Астафьев Е. Р., Голландский О. П., Копылов Н. М. Изд. Крым. астрофиз. обсерв., 40, 46-64 (1969).

7. Hutchings, J. B. Mon. Notic. Roy. Astron. Soc., 144, 235-295 (1959).

8. Luud, L., Ibrus, O., Kolka, I. Publ. Tartu AO, 39, 307-320 (1971).

9. Appenzeller, I. Astron. and Astrophys., 5, 355-371 (1970).

10. Appenzeller, I. Astron. and Astrophys., 9, 216-220 (1979).

11. Castor, J., Abbot, D. C., Klein, R. I. Astrophys. J., 195, 157-174 (1975).

12. Cassinelli, J. P., Olson, G. L., Stalio, R. Astrophys. J., 220, 573-581 (1978).

13. Wolf, B., Appenzeller, I. Astron. and Astrophys., 78, 15-20 (1979).

14. Лууд Л. Астрон. ж., 44, 267-277 (1967).

15. Лууд Л., Голландский О., Ярыгина T. Публ. Тартуск. астрофиз. обсерв., 43, 250255 (1975).

16. White, R. L., Becker, R. H. Bull. Amer. Astron. Soc., 13, 835 (1981).

Academy of Sciences of the Estonian SSR,

Institute of Astrophysics and Atmospheric Physics

Received

Bulgarian Academy of Sciences,

National Astronomical Observatory

Nevena MARKOVA, L. LUUD

\section{P CYGNI SPEKTRIJOONTE MUUTLIKKUS}

Homogeense spektrogrammide seeria alusel on leitud järgmist: 1) vesiniku spektrijoonte struktuur on väga keerukas, on vaadeldavad kuni neli neeldumiskomponenti; 2) kontuuride muutumise karakteerne aeg on kümneid päevi; 3) multipleti N II(5) neeldumisjoontel on paljukomponendiline püsiv struktuur; 4) kvalitatiivselt on kontuuride muutlikkus seletatav väljavoolava aine tükilise struktuuriga.

Невена МАРКОВА, Л. ЛУУД

\section{ИЗМЕНЕНИЯ КОНТУРОВ СПЕКТРАЛЬНЫХ ЛИНИИ Р ЛЕБЕДЯ}

Анализ однородной серии спектрограмм Р Лебедя показал следующее: 1) компоненты поглощения водородных линий имеют очень сложную структуру (вплоть до четырех составляющих); 2) характерное время изменения контуров порядка десятков дней: 3) линии поглощения мультиплета NII(5) указывают на мультикомпонентную, не изменяющуюся во времени структуру; 4) изменения контуров, видимо, обусловлены клочковатостью истекаюего вещества. 